sentative of our hallux or great toe, is turned backwards and articulates with a small distinct bone.

The heart has four perfectly distinct chambers, so that the pure blood from the lungs, and the impure blood from the rest of the body, are kept quite separate. There is a single aorta which turns to the right sicle after leaving the heart.

(To be contizulde)

\section{ON SAFETY MATCHES}

THE fact has been known during some years past that the so-called safety matches, which are warranted to ignite "only on the bcx," can be fired by being rubbed on glass, and as Mr. Preece recently pointed out (NATURE, vol. xiii. p. 208), on ebonite. I find that they can be ignited by friction against ivory (I used an ivory paper-knife), steel (a steel spatula, somewhat worn), zinc, copper, marble with the polish worn off, and a freshly-cleaved surface of slate.

The match (or two matches together, for the sake of strength) should be held near the tipped end, and then be rubbed with strong friction, and with a long sweep upon the solid surface. From two to twelve such sweeps may be required before the match ignites, and the result seems to be due to the conversion of mechanical work into heat sufficient to fire the paste at the end of the match, which, I suppose, consists mainly of potassic chlorate and sulphide of antimony.

After a few rubs the match begins to crackle, and then suddenly bursts into flame. A similar result may be obtained by grinding the chlorate in a mortar with a little sulphur or sulphide.

The readiness with which the match ignites by friction depends greatly on the nature of the surface. Lead is too soft, and tin too smooth. The metals produced by rolling have a sort of skin on the surface, over which the match glides without sufficient friction, but if the surface of zinc be rubbed with sand-paper or with a fine file, it becomes active in furing the match. I noticed that the polish of my ivory paper-knife became worn before it acted well. Nor is it very easy to fire the match on glass. A long sweep repeated about a dozen times with considerable pressure seems to be necessary. The two specimens of sheet copper used by me have a sort of grain which is favourable to the success of the experiment. The copper acted equally well whether the surface was dirty or cleaned with dilute sulphuric acid. After rubbing a match ten or twelve times on zinc, without effect, the same match rubbed on copper immediately took fire.

In the case of slate, lead, tin, and some other surfaces, the composition on the match acts as a polish, and thus renders it unfit for ignition. On the other hand, a finelycut file removes the composition from the end of the match without igniting it.

I have no doubt that many other surfaces might be found on which the safety matches would ignite with greater or less difficulty. Notwithstanding this, the match is still a safety match, although it does not comply with the conditions asserted twice over on the box. It does not ignite readily on any of the surfaces pointed out except copper and marble, but it does ignite with wonderful facility when rubbed against the side of the box, an invention so ingenious that a few words of its history may not be out of place here.

About the year $185^{\circ}$ a gentleman entered the laboratory of King's College, London, and drew from his waistcoat pocket a fragment of a rough-looking red solid, and, placing it in the hands of Prof. Miller, asked him if he knew what it was. It was handed round among those present, but no one had the slightest idea as to its nature, when, to the astonishment of every one, the gentleman said, "It is phosphorus-amorphous phosphorus, discovered by me, Herr Schrötter, of Vienna."
Up to this time, and indeed for some years later, persons engaged in the manufacture of lucifers were subject to a terrible disease, known in the London hospitals as " the jaw disease ;" necrosis of the lower jaw induced by constantly inhaling the fumes of phosphorus acid escaping from the phosphorus of the paste with which the matches were tipped.

Ordinary matches made with phosphorus were, during many years, dangerous contrivances. They were luminous in the dark, liable to ignition on a warm mantelpiece, poisonous; children have been killed by using them as playthings; and, moreover, they absorbed moisture, and became useless by age.

But the chief inducement in getting rid of ordinary phosphorus and substituting the new variety was to put an end, as far as possible, to the jaw disease. The red, or amorphous phosphorus, gave off no fumes, had no smell, was not poisonous, and the matches made with it were not luminous in the dark; they did not fire on a warm mantelpiece, did not contract damp, and would keep for any length of time. A manufacturer, in $185 \mathrm{r}$, sent me several samples of matches made with red phosphorus. I found some of these matches the other day, and they were as active, after twenty-five years, as at first.

But here was a difficulty. When the red phosphorus is brought into contact with potassic chlorate a slight touch is sufficient to produce an explosion, in which the red phosphorus reassumes its ordinary condition. Many attempts were made to form a paste, and many accidents and some deaths occurred in consequence. Prizes and rewards were offered by manufacturers and others for a safe paste, or for some means of using the red instead of the ordinary phosphorus, but without success, so that the patent for the manufacture of red phosphorus, which was secured by Mr. Albright, of Birmingham, in $185 \mathrm{r}$, threatened to be of but little value.

At length the happy idea occurred to a Swedish manufacturer not to attempt to make a paste at all with the red phosphorus, but to make the consumer bring the essential ingredients together in the act of igniting the match.

Mr. Preece's suggestion that the ignition of the matches is due to electricity, may be dismissed in the face of the following experiment:- Place a few grains of red phosphorus on a hard surface together with some powder or a crystal of potassic chlorate, when a gentle tap will cause them to burst into a flame.

C. TOMLINSON

\section{NOTES FROM SIBERIA}

THE following Siberian notes are furnished me by a Polish gentleman resident at Irkutsk. The dates mentioned follow the Old System, as in Russia, and are twelve days behind our own dates. The letter is dated the roth of February. My informant says :-

"Some time ago Mr. Czckanofski returned from his second expedition to the most northern parts of Siberia by the Olensk River. He went as far as its mouth, and the extraordinarily warm autumn gave him the opportunity to make very interesting explorations. Till the month of September there was no frost nor snow, and the sea not frozen. The same is reported by Mr. Neumann, who returned lately from the Behring Strait. It may be that these exceptional climatical conditions allowed also Mr. Nordenskjöld's entering the mouth of the Jenessei. The exploration in the Achinsk country of a cavern situated now some thirty fathoms above the bed of the river gave to $\mathrm{Mr}$. Tskersky ${ }^{1}$ a fine collection of wellconserved fossils of extinct species. Mr. Tskersky occupies himself now with the description of the Tunka Alps, which he believes to be the former boundary of Lake Baikal, as he found there the fossils of the crab and

I The Curator of the Museum at Irkutsk.-G, F. 
seals. ${ }^{1}$ Dr. Dybowsky passed a year on the Ussour River, and brought a beautiful collection of birds, fish, and quadruped skeletons. His descriptions are sent to the Berlin Museum. Now he is occupied upon the Baikal with soundings and observations on the Baikal seals. He wishes to write a monograph on this particular species of seals. This is nearly all that was done last year, as far as expeditions are concerned, in this part of the world."

My correspondent refers me to the proceedings of the Siberian Geographical Society for further details. It is much to be regretted that this publication, as well as the excellent Calendar of Eastern Siberia are so little known, out of Asia. I further learn that earthquake shocks have been $f$ it at Irkutsk on the $4^{\text {th }}$ of September last, at 2.55 A.M., and a slight one on the $4^{\text {th }}$ of January. The first one came from the east. A clock which was secured by screw's almost an inch long, was left leaning on one side, and both of the screws drawn completely out of the wall. The Baikal district is the spot in Northern Asia which is most visited by earthquakes.

Since I am on the subject of Siberia, I may mention two facts of considerable interest which I learnt last year. I was told by inhabitants of Jenesseisk that in the regions to the north of that town the compass is of no use during an auroral display. It is not at all unlikely that this should be the case in a country where auroral effects are intense, and the horizontal component of the earth's magnetism is small. The other interesting fact is that Mr. Muller had reached Gauss' Siberian magnetic pole, where he found the needle vertical. This was shortly before I reached Irkutsk. His observations were to be published in the Proceedings of the Siberian Geographical Society. I do not know whether a translation has been published.

Andersonian University, Glasgow, April 4

\section{THE DUBLIN SOCIETIES}

W

W have recently refered in several articles to the efforss which are being made to introduce a more satisfaciory organisation among the various scientific institutions in Dublin, which have hitherto been independent of each other. It appears now to be proposed not merely to unite museums, but to unite into one body the Royal Irish Academy and the Royal Dublin Society. This project would se $\because \mathrm{m}$ to have originated at a meeting which a deputation from the latter body had with Major Dunnelly. It is evident that many difficulties would be removed and many advantages result from the amalgamation of these two societies. Of course the arrangements for such an amalgamation must be carried out entirely by the societies, though it would no doubt tend to forward such a scheme if the societies were assured of the approval of Government, and of such aid towards taking the necessary steps as the Government has in its power to give.

We understand further that there is some possibility of an amalgamation of the Royal Agricultural Society of Ireland with the Royal Dublin Society. It is most desirable that such an amalgamation should be effected, and that the agricultural shows should be removed from the present bulldings beside Leinster House to the Phøenix Park.

From a letter which has been published in the Irish papers, it appears that these points have been submitted by Major Donnelly to Lord Sandon, who has informed him that the Government are prepared to aid the amalgamation and to give the necessary space in the Phonix Park.

Should the amalgamation be effected, it would probably

I Lake Baikal is remarkable, among other things, for the presence of these marine animals. The seals are grey, and have a very coarse fur. I took a photograph last summer of one which was in the Museum at Irliutsk. take the form of a new Society with a limited number of Fellows, ordinary members, and an Arricultural Section.

It is possible enough that some of the members of the Royal Irish Academy may object to the proposed change, on the score that they would thus lose caste. We cannot adrnit the validity of such an objection. The Academy has no doubt done good work, but it has a large number of members on its roll who are no more entitled to any scientific or literary distinction than the general body of the members of the Royal Dublin Society. If, however, the Academy consent to the proposed change, the Fellowship of the new Society would become a high and much-coveted honour, and the reputation of the whole body would be far higher than that of the separate societies is now. As to the objection that the large body of general members are unfit to select Fellows, we think that the Fellows may very well be entrusted with the selection of Fellows; the first Fellows under the new charter might be, say Fellows of Trinity College, Dublin, Professors and ex-Professors of a College or University, and others with similar positions, who should be empowered to choose their successors. There need be no difficulty, while acting with perfect fairness and openness, in choosing for the inner circle and also for the governing body the best men of the new society, men who would make a point of maintaining its honour and dignity. The Royal Irish Academy would thus become, under a new name, a select body of Fellows chosen for their scientific and literary merit; in time, indeed, this fellowship might come to be regarded as an honour little inferior to that of F.R.S.

The union of the societies would remove many diffculties as to ownership of property, and would place at their disposal a much larger amount of funds for scientific and literary work than they at present possess. Indeed, it appears to us that from the union on the proposed basis, nothing but good could result, great benefits to the meinbers, and much greater advantages than at present exist for the promotion of science in Ireland. Since government has promised to aid the United Society as far as possible, we think it would be a pity if any petty spirit of local jealousy should raise obstructions to the accomplishment of a scheme which promises so well for the country.

\section{GERMANY AND THE LOAN EXHIBITION}

THE German Committee for the London Loan Exhibition of Scientific Apparatus has addressed a report to the Crown Prince and Crown Princess of Germany on the success of their efforts. It results from this document that 3 I I German exhibitors will be represented by 2,492 objects. The 19 classes will be represented as follows :-

\begin{tabular}{|c|c|c|c|c|c|c|}
\hline \multirow{2}{*}{ Arithmetic by ... } & \multirow{2}{*}{$\begin{array}{l}\ldots \\
\ldots\end{array}$} & \multicolumn{3}{|c|}{6 exhibitors a } & \multicolumn{2}{|c|}{ I I object } \\
\hline & & $\ldots 13$ &, & $"$ & 35 & \\
\hline 3. Measurement by & $\ldots$ & ... 59 & $"$ & ," & 126 & \\
\hline 4. Kinematics by & & ... ro & $"$ & , & 308 & \\
\hline 5. Molecular Physics & & $\ldots 23$ & $"$ & $"$ & 33 & \\
\hline 6. Sound by $\ldots \quad \ldots$ & $\cdots$ & ... 10 & $;$ & , & 24 & \\
\hline 7. Light by $\ldots$... & $\ldots$ & .. 35 & ," & $"$ & II 8 & \\
\hline 8. Heat by $\ldots$ & $\ldots$ & $\ldots 19$ & ", & $"$ & $4 \mathrm{I}$ & \\
\hline o. Electricity by .. & $\cdots$ & $\cdots 32$ & ", & $"$ & 194 & \\
\hline Astronomy by ... & $\ldots$ & ... 25 & " & $"$ & 78 & \\
\hline - Applied Mechanics & by & ... 13 & $"$ &, & 64 & \\
\hline 3. Chemistry ${ }^{1}$ by $\ldots$ & $\cdots$ & $\cdots 32$ & " & ", & 389 & \\
\hline 4. Meteorology by & $\cdots$ & $\ldots$ IS & ", & , & 49 & \\
\hline Geograpluy by ... & .. & ‥29 & $"$ & 3 & 110 & \\
\hline -. Geology by & $\cdots$ & 22 & $"$ & ", & IIS & \\
\hline Mineralogy by ... & $\cdots$ & ‥ 19 & ", & "' & 39 & \\
\hline $\begin{array}{l}\text { r8. Biology by } \\
\text { 19. Education: }\end{array}$ & & $\ldots 34$ & ," & & 441 & \\
\hline & & & & & & \\
\hline
\end{tabular}

The space claimed by the exhibitors will be rog square metres floor, 442 square metres repositories (tables, \&c.), 299 square metres wall. Considering that two months had to suffice for bringing together this collection, that manu-

I Exclusive of the collective exhibition of the German Chemical Society, which will represent about 40 exhibitors with 300 objects. 